\title{
Precauções e Recomendações sobre Sedação Odontológica durante a Pandemia de COVID-19
}

\author{
Rafael Celestino Colombo Souza, ${ }^{1}$ Paulo Sucasas Costa, ${ }^{2}$ Luciane Rezende Costa ${ }^{3}$ \\ ${ }^{1}$ Faculdade de Odontologia São Leopoldo Mandic, Campinas, SP, Brasil. \\ ${ }^{2}$ Faculdade de Medicina, Universidade Federal de Goiás (UFG), Goiânia, GO, Brasil. \\ ${ }^{3}$ Faculdade de Odontologia, Universidade Federal de Goiás (UFG), Goiânia, GO, Brasil. \\ - Os autores declaram que não há conflito de interesses
}

\section{Prezado Editor,}

A publicação "Doença pelo Coronavírus 2019 (COVID-19): Uma abordagem preventiva para Odontologia"1 é oportuna e relevante. Percebe-se, no entanto, que as recomendações sobre a relação entre sedação em odontologia e COVID-19 não estão claras em nenhum protocolo ou diretrizes. No presente artigo, buscamos direcionar os conceitos apresentados naquela revisão ${ }^{1}$ e em literatura adicional para sistematizar recomendações para a prática da sedação em consultório odontológico durante esta pandemia.

Evidências sobre disseminação do novo coronavírus

Até hoje, 3 de abril de 2020, 18 horas e 36 minutos, foram relatados 1.093.107 casos de COVID-19 e 58.729 óbitos pela doença no mundo. No Brasil, a frequência respectiva corresponde a 9.056 casos e 359 óbitos. Com base nos dados atuais, a taxa de letalidade pelo novo coronavírus (SARSCoV-2 - Coronavírus da Síndrome Respiratória Aguda Grave 2/Severe Acute Respiratory Syndrome Coronavirus 2) é estimada em 3,4\%. ${ }^{2}$ Esses dados são atualizados diariamente tendo em vista a rápida progressão dos números.

Como o número de casos apresenta crescimento exponencial e é um problema de ordem mundial, a Organização Mundial de Saúde (OMS) declarou, em 11 de março de 2020, que a COVID-19 é, de fato, uma pandemia, ou seja, relaciona-se a disseminação mundial, com transmissão sustentada, de uma nova doença. ${ }^{3}$

Uma parte dos infectados são assintomáticos, e $80 \%$ daqueles que desenvolvem sintomas têm uma forma leve da doença. ${ }^{2}$ Então, a COVID-19 pode se apresentar como estado de portador assintomático do SARS-CoV-2, ou sintomático com doença respiratória aguda, chegando à pneumonia $\mathrm{e}$ óbito. ${ }^{4}$ Casos de COVID-19 não identificados são responsáveis pela infecção de $79 \%$ dos casos documentados. ${ }^{5}$

A transmissão da COVID-19 ocorre por meio da exposição das mucosas ocular, nasal e oral com gotículas/aerossóis contendo SARS-CoV-2, oriundos de secreções de vias aéreas, saliva ou sangue. ${ }^{1}$ Desse modo, a COVID-19 apresenta também um alto risco para os profissionais de saúde no ambiente perioperatório - consultórios, ambulatórios, salas de emergência e unidades de terapia intensiva. ${ }^{6} \mathrm{~A}$ expressiva carga viral concentrada nas vias aéreas superiores tem levado a grande disseminação da doença entre profissionais que lidam na região de cabeça e pescoço, incluindo o cirurgiãodentista, além de oftalmologistas, otorrinolaringologistas, endoscopistas e cirurgiões, a despeito de medidas de precaução estabelecidas. ${ }^{7}$ Com isso, é imperativo a adoção de procedimentos operacionais padrão para o bloqueio da transmissão perioperatória do SARS-CoV-2.

Diretrizes gerais para manejo da aerossolização em ambientes de saúde

Sabidamente, a prática odontológica se associa à geração de gotículas e aerossóis, por meio da névoa da seringa tríplice, uso de motor com spray, jato de bicarbonato e ultrassom, dentre outros, o que favorece a disseminação do vírus. ${ }^{1}$

Em 31 de março de 2020, a Agência Nacional de Vigilância Sanitária (ANVISA) atualizou a Nota Técnica GVIMS/GGTES/ANVISA nº 04/2020, com apoio técnico do Conselho Federal de Odontologia, a qual orienta os serviços de saúde sobre medidas de prevenção e controle que devem ser adotadas durante a assistência aos casos suspeitos ou confirmados de infecção pelo novo coronavírus (SARS$\mathrm{CoV}-2$ ), incluindo o atendimento odontológico. ${ }^{8}$ Destaca-se, dentre tais orientações: os procedimentos que podem gerar aerossóis devem ser realizados, preferencialmente, em uma unidade de isolamento respiratório com pressão negativa e filtro HEPA (High Efficiency Particulate Arrestance); o cirurgião-dentista deve postergar procedimentos eletivos e realizar apenas procedimentos de urgência ou emergência, utilizando medidas para minimizar a geração de aerossóis e respingos salivares e de sangue. ${ }^{8}$

Então, constata-se que o atendimento odontológico durante a pandemia da COVID-19, restrito aos casos de urgência e emergência, apresenta alto risco de transmissão nosocomial entre pacientes e equipe odontológica, ainda que se utilize adequadamente os equipamentos de proteção individual e demais medidas de minimização de contato e geração de aerossóis. 
Assim como em odontologia, procedimentos de anestesiologia podem gerar aerossóis, como: intubação orotraqueal, ventilação mecânica não invasiva e oxigenação de alto fluxo. ${ }^{9,10}$ A mesma nota técnica da ANVISA também indica que os procedimentos de anestesia eletivos sejam suspensos temporariamente durante a fase de pandemia. ${ }^{8}$ Adicionalmente, a Sociedade Brasileira de Anestesiologia recomenda que: os procedimentos de sedação e anestesia geral, quando necessários, sejam realizados por meio de circuitos de aspiração fechados; os pacientes contaminados ou com suspeita de contaminação pela COVID-19 sejam tratados com um aparelho de anestesia dedicado (específico) para eles; os materiais anestésicos reutilizáveis sejam processados de acordo com as normas da Comissão de Controle de Infecção Hospitalar, após cada utilização; e as traquéias utilizadas sejam descartáveis. ${ }^{9}$

Vale ilustrar que os pacientes com COVID-19 com insuficiência respiratória aguda são tratados em leitos de isolamento com pressão negativa (se disponível) com oxigênio de baixo fluxo via cateter nasal (até 5 litros/minuto), para minimizar a disseminação de gotículas e aerossóis. Porém, se essa terapia não for suficiente, os pacientes são submetidos à intubação precoce, pelo potencial de aerossolização e contaminação dos profissionais. É uma recomendação inédita de se clampear a extremidade distal da cânula de intubação e evitar a ventilação assistida manual com o dispositivo de bolsa-válvula-máscara (AMBU), mesmo com queda da saturação de oxigênio, até a conexão definitiva ao ventilador mecânico. A ventilação não-invasiva, para esses pacientes, é extremamente restrita e realizada em unidades de terapia intensiva com recursos humanos e físicos devidamente preparados para controlar contaminação nosocomial pelo vírus. ${ }^{11}$

Assim, a sedação em consultório odontológico merece especial atenção durante a pandemia de COVID-19. A sedação inalatória com óxido nitroso e oxigênio, por exemplo, provoca aerossóis pelo fluxo de gases em um circuito semifechado, que frequentemente ultrapassam o volume de 5 litros por minuto, os quais facilmente chegam ao ambiente também pelo selamento da máscara nasal não ser perfeito. ${ }^{12} \mathrm{~A}$ contaminação pelos gases óxido nitroso e oxigênio pode atingir até 2 metros do raio em que a máscara nasal é instalada; desta forma, pode conduzir aerossóis para superfícies de móveis e equipamentos, além da contaminação direta ao profissional e equipe e, no caso das crianças e pacientes com necessidades especiais, aos seus acompanhantes. A sedação enteral ou parenteral,se realizada sem oxigênio suplementar, não levaria a aerossóis adicionais no contexto odontológico. Todavia considera-se que qualquer procedimento sob sedação pode necessitar de medidas de suporte básico de vida para controlar evento adverso cardiorrespiratório e assim gerar aerossóis. Ou seja, a sedação se configura em mais um risco de disseminação do
SARS-CoV-2 em odontologia.

\section{Questões éticas}

No contexto da atenção em saúde em fase de pandemia, entende-se que todas as pessoas devam ser tratadas como suspeitas de serem portadoras do SARS-CoV-2, pois os testes de confirmação da doença são insuficientes e há os casos assintomáticos ou ainda em fase inicial da doença que também podem transmitir o vírus.

A escassez de recursos para lidar com a pandemia também é observada na falta de leitos em unidades de terapia intensiva, medicamentos essenciais e ventiladores, aumento da demanda de pacientes no sistema de saúde e adoecimento dos profissionais que atuam na linha de frente no combate à COVID-19.

Enquanto isso, o conhecimento sobre a etiopatogenia, prevenção e tratamento da COVID-19 estão em construção, haja vista a novidade da doença. Resta ao profissional de saúde guiar-se pela máxima "primum non nocere" - expressão latina que significa "primeiro, não prejudicar", representada no juramento hipocrático professado pelos profissionais de saúde por ocasião de sua graduação. Nesse sentido, também o cirurgião-dentista deve se pautar por evitar riscos, danos e custos desnecessários aos pacientes, equipe de saúde e à sociedade, ao considerar que "evitar a transmissão da COVID-2019 ainda é o esforço mais eficiente de saúde pública para diminuir o seu impacto". ${ }^{6}$

A prática da sedação em odontologia compreende, além da competência profissional, o uso de infraestrutura adequada que envolve a contratação de fornecimento de gases medicinais e seus respectivos cilindros acondicionantes, os quais podem ser necessários para pacientes infectados hospitalizados e graves, tanto na rede pública ou privada. Também, deve-se prever possíveis complicações da sedação e, por consequência, necessidade de encaminhamento de pacientes a hospitais (nível secundário de atenção) e, assim, gerar possível sobrecarga para o serviço público e privado de saúde, cujos escassos recursos humanos e estruturais estão temporariamente voltados ao combate da COVID-19.

\section{Conclusão}

Isso posto, para manejo do paciente com ansiedade severa, ou fóbico, na consulta de urgência/emergência em odontologia, recomenda-se:

1. Utilizar técnicas não-farmacológicas para controlar a ansiedade do paciente, acompanhadas ou não de estabilização protetora (crianças e pessoas com deficiência), com uso de técnicas de odontologia de mínima intervenção, quando indicadas. ${ }^{13}$

2. Realizar, nos casos graves, atendimento odontológico sob anestesia geral, utilizando técnicas resolutivas para solução do problema odontológico do paciente, que evitem retornos ou tratamentos adicionais em curto prazo. 
3. Não realizar procedimentos odontológicos sob sedação inalatória com óxido nitroso/oxigênio durante a pandemia de COVID-19, com o objetivo de mitigar a aerossolização e a disseminação do vírus, e ao potencial risco de necessitar de medidas de suporte de vida que envolvem manipulação de vias aéreas e uso de rede hospitalar.
4. Não realizar procedimentos odontológicos sob sedação medicamentosa, devido à necessidade de disponibilização de oxigênio e ao potencial risco de necessitar de medidas de suporte de vida que envolvem manipulação de vias aéreas e uso de rede hospitalar.

\section{References}

1. Tuñas ITC, Silva ET, Santiago SBS, Maia KD, Silva-Júnior GO. Doença pelo Coronavírus 2019 (COVID-19): Uma abordagem preventiva para Odontologia. Rev Bras Odontol. 2020;77:e1766.

2. Worldometer's Covid-19 data. Disponível em: <www.worldometers.info/coronavirus/\#countries $>$ Acesso em: 03 de abr. de 2020.

3. World Health Organization. Coronavirus disease (COVID-19) pandemic. Disponível em: <https://www.who.int/emergencies/diseases/novel-coronavirus-2019> Acesso em: 03 de abr. de 2020.

4. Lai CC, Liu YH, Wang CY, Wang YH, Hsueh SC, Yen MY, et al. Asymptomatic carrier state, acute respiratory disease, and pneumonia due to severe acute respiratory syndrome coronavirus 2 (SARS-CoV-2): Facts and myths. J Microbiol Immunol Infect. 2020;pii:S1684-1182(20):30040-2.

5. Li R, Pei S, Chen B, Song Y, Zhang T, Yang W, et al. Substantial undocumented infection facilitates the rapid dissemination of novel coronavirus (SARS-CoV2). Science 2020;pii:eabb3221.

6. Zucco L, Levy N, Ketchandji D, Aziz M, Ramachandran SK. Perioperative Considerations for the 2019 Novel Coronavirus (COVID-19). Anesthesia Patient Safety Foundation, Disponível em: <https://www.apsf.org/news-updates/perioperative-considerations-for-the-2019-novel-coronavirus-covid-19/> Acesso em: 03 de abr. de 2020.

7. Kulcsar MA, Montenegro FL, Arap SS, Tavares MR, Kowalski LP. Alto risco de infecção por COVID-19 para cirurgiões de cabeça e pescoço. Sociedade Brasileira de Cirurgia de Cabeça e Pescoço. Disponível em: <http://sbccp.org.br/altorisco-de-infeccao-por-covid-19-para-cirurgioes-de-cabeca-e-pescoco/>. Acesso em: 04 de abr. de 2020.
8. Agência Nacional de Vigilância Sanitária. Nota Técnica GVIMS/GGTES/ ANVISA No 04/2020: Orientações para serviços de saúde: medidas de prevenção e controle que devem ser adotadas durante a assistência aos casos suspeitos ou confirmados de infecção pelo novo coronavírus (SARS-CoV-2). 31.03.2020. Disponível em: <http://website.cfo.org.br/wp-content/uploads/2020/04/Nota-Tecnica-Anvisa-CFO-contra-covid-19.pdf $>$ Acesso em 03 de abr. de 2020.

9. Sociedade Brasileira de Anestesiologia. O coronavírus e o anestesiologista. 2. ed. Atualização em 19/03/2020. Disponível em: <https://www.sbahq.org/ebook/> Acesso em: 03 de abr. de 2020.

10. Chen X, Liu Y, Gong Y, Guo X, Zuo M, Li J, et al. Perioperative management of patients infected with the novel coronavirus: Recommendation from the Joint Task Force of the Chinese Society of Anesthesiology and the Chinese Association of Anesthesiologists. Anesthesiology. In press 2020.

11. Associação de Medicina Intensiva Brasileira. Orientações sobre o manuseio do paciente com pneumonia e insuficiência respiratória devido a infecção pelo Coronavírus (SARS-CoV-2) - Versão n.03/2020*. Disponível em: <https:// www.amib.org.br/fileadmin/user_upload/amib/2020/marco/29/Orientacoes_ sobre_o_manuseio_do_paciente_com_pneumonia_e_insuficiencia_respiratoria_devido_a_infeccao_pelo_Coronavirus_SARS-CoV-2_-_Versao_n.032020. pdf $>$. Acesso em: 04 de abr. de 2020.

12. Organization for Safety Asepsis and Prevention. Nitrous oxide toolkit. Disponível em: <https://www.osap.org/page/Issues_NitrousOxide?page=SegmentEducators $>$ Acesso em: 03 de abr. de 2020.

13. Mallineni SK, Innes NP, Raggio DP, Araujo MP, Robertson MD, Jayaraman J. Coronavirus Disease (COVID-19): Characteristics in children and considerations for Dentists providing their care. Int J Paediatr Dent. In press 2020.

\section{Mini Curriculum e Contribuições dos Autores:}

1. Rafael Celestino Colombo de Souza - Cirurgião-Dentista;Doutor em Odontologia. Contribuição: Participação da concepção, hipótese, preparação e redação do manuscrito e revisão crítica. ORCID: 0000-0002-5287-8048

2. Paulo Sucasas Costa - Médico;Doutor em Medicina. Contribuição: Participação científica e intelectual efetiva do estudo; preparação e redação do manuscrito; revisão crítica e aprovação final. ORCID: 0000-0001-9370-9139

3. Luciane Rezende Costa - Cirurgiã-Dentista;Doutor em Odontologia. Contribuição: Participação científica e intelectual efetiva do estudo; preparação e redação do manuscrito; revisão crítica e aprovação final. ORCID: 0000-0001-7637-0049

Submetido:05/04/2020 / Aceito para publicação: 07/04/2020

Autor Correpondente:

Luciane Rezende Costa

E-mail: Isucasas@ufg.br 